\title{
Effect of Age and Gender on Incidence of Post Spinal Headache
}

\author{
Rachana Gandhi', Alka Shah', ,lla Patel ${ }^{3}$ \\ ${ }^{1,2}$ Associate Professor, Department of Anaesthesiology, GMERS Medical College \& Civil Hospital, Sola, Ahmedabad, Gujarat, India, ${ }^{3}$ Professor, \\ Department of Anaesthesiology, GMERS Medical College \& Civil Hospital, Sola, Ahmedabad, Gujarat, India.
}

\section{Abstract}

Background: Post spinal headache is a common complication after spinal anaesthesia, lumbar puncture and myelography. The aim of study is to calculate the incidence of post dural puncture headache in non-obstetric patients coming to the GMERS Medical College and civil hospital, sola, Ahmedabad. Subjects and Methods: A prospective observational study was conducted on 150 patients of ASA grade I and II admitted in the department of general surgery, orthopedic and gynecology under spinal anaesthesia. All patients were interviewed after 12 hours, 24 hours, 36 hour, 48 hours, 60 hours and 72 hours as regard to headache, its severity, location character, duration, associated symptoms like nausea, vomiting, auditory and ocular symptoms. PDPH was treated initially conservatively with bed rest, hydration and analgesic (injection diclofenac $75 \mathrm{mg}$ ). If the PDPH persisted longer than 24 hour with same severity, and epidural blood patch was considered before discharged from hospital. Results \& Conclusion: The overall incidence of PDPH in Civil Hospital, Sola, and Ahmedabad was 8.06\%. The incidence of PDPH in young patients was $12.12 \%$ and in old patients were $3.44 \%$. The incidence of PDPH in female was $12.5 \%$ and in male was $4.08 \%$. Thus female significantly have more risk of developing PDPH. The onset of PDPH after dural puncture among the patients who develop PDPH occurred within 24 hours in 33.3\%, within 30 hours in $40 \%$ and within 36 hours in $26.6 \%$ of patients. PDPH was most commonly located in occipital region in $60 \%$ of patients. Severity of PDPH was mild to moderate. In $73.3 \%$ of patients the maximum severity was grade II. Nausea and vomiting was associated with severe PDPH. No patients develop any other associated symptoms.

Keywords: Post spinal headache, CSF, spinal needle, diclofenac.

Corresponding Author: Dr. Alka Shah, B-301, Swaminarayan Castel-1, NR. Arjun Ashram, Opp. Green City, Chandlodia, Ahmedabad.

Received: March 2019

Accepted: March 2019

\section{Introduction}

Post spinal headache is a common complication after spinal anaesthesia, lumbar puncture and myelography. It is debilitating to the patients and can significantly interfere with the functional capacity and post-operative well-being. The actual mechanism producing the headache is unclear. There are two possible explanations. First, decrease in CSF pressure may cause traction on pain sensitive intracranial structure in the upright position, leading to the characteristic headache. Secondly, the loss of CSF may cause a compensatory vasodilatation. The cushioning effect of the fluid disappears and tension is applied directly to the cranial structure sensitive to pain. ${ }^{[1,2]}$

Headache following spinal anaesthesia i.e. PDPH, which may be incapacitating is bifrontal and occipital and may involve the neck and upper shoulders. It is aggravated by sitting, standing, coughing and straining but subsides completely when the patient lies down. It is often accompanied by nausea, anorexia, photophobia, diplopia, vertigo and neck stiffness. And on rare occasion, cranial nerve palsies. Postdural puncture headache (PDPH) usually occur within the three days of dural puncture and may persist for several weeks or even months causing depression in the patients and anxiety in the anaesthetist. ${ }^{[3,4]}$
The most important factors influencing the frequency and severity of PDPH are the patient's age, spinal needle size and bevel design and bevel orientation. Female gender has also been linked to PDPH.

\section{Subjects and Methods}

A prospective observational study was conducted on 150 patients of ASA grade I and II admitted in the department of general surgery, orthopedic and gynecology of GMERS Medical College, Hospital, Sola and Ahmedabad during the year 2014 after obtaining approval of institutional ethics committee and written informed consent.

Patient with ages 20 to 65 years, both male and female, and physical status ASA I and II were included in study. Patient refusal, chronic illness (i.e. ischemic heart diseases, diabetes mellitus, bronchial asthma, bronchitis, sinusitis), chronic headache like migraine, hyper tension, previously operated under spinal anaesthesia with past history of PDPH, patients with multiple dural puncture during procedure, patient having physical status ASA III and IV, patient having any spinal deformity and patient having contraindication of spinal anaesthesia were excluded in this study.

Patient was visited a day before surgery for Preanesthetic evaluation and thorough clinical history and examination was done. The procedure was explained to all patients during 
their preoperative visit and an informed written consent was obtained from each patients. All necessary investigation was done as per institutional protocol. Patients were premedicated with tablet alprazolam $0.25 \mathrm{mg}$ a night before surgery unless contraindicated. On the day of surgery injection ranitidine $50 \mathrm{mg}$ and injection ondensetron $4 \mathrm{mg}$ intravenously were given one hour before surgery.

On arrival to operative room wide bore IV cannula was secured. Standard monitoring like NIBP, ECG, Sp02 were attached and all baseline parameters were recorded. All patients were preloaded with 15 to $20 \mathrm{ml} / \mathrm{kg}$ of ringer lactate solution prior to spinal anaesthesia. Under all aseptic precautions by experienced anaesthesiologist lumbar puncture was performed. After locating L2 - L3 or L3 - L4 interspace in the midline local anaesthetic solution was infiltrated. Lumbar puncture was performed with 25 gauze quinckie needle in lateral decubitus position with bevel facing parallel to the direction of dural fibers in all patients. Those patients were excluded from the study that underwent second dural puncture. After demonstration of free flow of clear cerebrospinal fluid, hyperbaric bupivacaine $0.5 \% 3$ to $3.5 \mathrm{ml}$ was injected slowly with needle's bevel facing cephalad. After withdrawal of the needle, all the patients turned in supine position for 30 minutes, after which they were placed in required surgical position. Level of sensory blockade and changes in parameters like heart rate, BP were recorded. Solution of ringer lactate, normal saline, colloid and blood were transfused as maintenance fluid and also according to the blood loss. Hypotension (defined as fall in blood pressure below $20 \%$ of baseline) was treated with bolus IV fluids and $6 \mathrm{mg}$ injection mephentermine intravenously. Complications like nausea, vomiting, bradycardia, respiratory depression, skin reaction was manages symptomatically.

After surgery all patients were shifted to the post anaesthesia care unit with all necessary monitoring. Patients were mobilized after hemodynamic stability, return of sensation and all signs of motor blockade were disappeared. Adequate hydration and bed rest were taken care off. All patients were given slight head low position.

All patients were interviewed after 12 hours, 24 hours, 36 hour, 48 hours, 60 hours and 72 hours as regard to headache, its severity, location character, duration, associated symptoms like nausea, vomiting, auditory and ocular symptoms. PDPH was defined as the occipital, frontal or generalized headache brought on by erect posture and relieved when supine position was resumed.

Patients with a headache were evaluated for the severity and duration of the headache and there response to treatment. PDPH was treated initially conservatively with bed rest, hydration and analgesic (injection diclofenac $75 \mathrm{mg}$ ). If the PDPH persisted longer than 24 hour with same severity, and epidural blood patch was considered before discharged from hospital.

\section{Results}

A total 186 patients were recruited in the study. All patients were as grade I and II posted for lower abdominal, gynecological and lower limb orthopedic surgeries under spinal anaesthesia. All patients were given spinal anaesthesia with $25 \mathrm{G}$ Quincke needle. No obstetrical patients were included in our study. Demographic data of patients are shown in [Tables 1 and 2].

Demographically both age groups were comparable with respect to sex, height, weight and BMI. Both gender groups age is comparable were as there is some difference in height, weight and BMI. This difference can be expected due to normal anatomical and physiological difference in both genders.

PDPH cases were initially treated with bed rest and oral or intravenous hydration. Patients were treated with intravenous injection diclofenac $75 \mathrm{mg}$ when headache was moderate to severe. Total dose of diclofenac required for each patient was noted. All the patients who develop PDPH responded well to the treatment.

The maximum severity of headache in all patients varies between grade II to grade III. None of patient in the both the age group have very severe headache of grade IV. The time of onset of development of PDPH was between 24 to 48 hours after dural puncture. None of patients develop PDPH after 24 hours.

\begin{tabular}{|l|l|l|}
\hline Table 1: Demographic data for both age groups. \\
\hline & YOUNG AGE $(\mathbf{n = 9 9 )}$ & OLD AGE $(\mathbf{n}=\mathbf{8 7})$ \\
\hline Sex $(\mathrm{M} / \mathrm{F})$ & $56 / 43$ & $42 / 45$ \\
\hline Height $(\mathrm{cm})$ & $159 \pm 8.11$ & $158 \pm 9.4$ \\
\hline Weight $(\mathrm{kg})$ & $59.1 \pm 7.77$ & $62 \pm 10.39$ \\
\hline BMI $(\mathrm{kg} / \mathrm{m} 2)$ & $23.4 \pm 1.62$ & $24.6 \pm 2.28$ \\
\hline
\end{tabular}

Table 2: Demographic data for both gender groups

\begin{tabular}{|l|l|l|}
\hline & MALE$(\mathbf{n}=99)$ & FEMALE $(\mathbf{n = 8 8})$ \\
\hline Age $(\mathrm{yr})$ & $35.1 \pm 13.8$ & $34.9 \pm 10.5$ \\
\hline Height $(\mathrm{cm})$ & $165 \pm 5.25$ & $151 \pm 5.08$ \\
\hline Weight $(\mathrm{kg})$ & $66.4 \pm 7.78$ & $53.9 \pm 5.36$ \\
\hline BMI $(\mathrm{kg} / \mathrm{m} 2)$ & $24.43 \pm 2.02$ & $23.46 \pm 1.94$ \\
\hline
\end{tabular}

Table 3: showing the incidence of PDPH in the two age groups

\begin{tabular}{|l|l|l|l|}
\hline Age distribution & With PDPH & Without PDPH & Total \\
\hline
\end{tabular}

\begin{tabular}{|c|c|c|c|}
\hline 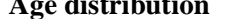 & mingeren & move & Hotas \\
\hline $\begin{array}{l}\text { Young age (20- } \\
\text { 35year) }\end{array}$ & $12(12.1 \%)$ & $87(87.8 \%)$ & 99 \\
\hline $\begin{array}{l}\text { Old age (35-65 } \\
\text { year) }\end{array}$ & $3(3.4 \%)$ & $84(96.5 \%)$ & 87 \\
\hline Total & $15(8.06 \%)$ & 171(91.9\%) & 186 \\
\hline
\end{tabular}

$\mathrm{P}=0.030(<0.05)$ significant. The difference in the incidence of PDPH was statistically significant in two age groups.

Table 4: showing the incidence of PDPH in the two gender groups

\begin{tabular}{|l|l|l|l|}
\hline & With PDPH & Without PDPH & Total \\
\hline Male & $4(4.08)$ & $94(95.9)$ & 98 \\
\hline Female & $11(12.5)$ & $77(87.5)$ & 88 \\
\hline Total & $15(8.06)$ & $171(91.9)$ & 186 \\
\hline
\end{tabular}

$\mathrm{P}=0.035(<0.05)$ significant. In our study female has 3 times more incidence of PDPH than male was statistically significant in two gender groups.

Table 5: showing maximum severity of PDPH

\begin{tabular}{|l|l|}
\hline Grade of headache & No. of patients \\
\hline Mild (grade I) & 0 \\
\hline Moderate (grade II) & $11(73.3 \%)$ \\
\hline Severe (grade III) & $4(26.6 \%)$ \\
\hline Very severe (grade IV) & 0 \\
\hline
\end{tabular}


Table 6: showing the time of onset of PDPH in 186 patients

\begin{tabular}{|l|l|}
\hline Time & No of patients \\
\hline 24 hours & $5(33.3 \%)$ \\
\hline 30 hours & $6(40 \%)$ \\
\hline 36 hours & $4(26.6 \%)$ \\
\hline 48 hours & 0 \\
\hline 60 hours & 0 \\
\hline 72 hours & 0 \\
\hline
\end{tabular}

Table 7: Location of PDPH in 186 patients

\begin{tabular}{|l|l|}
\hline Location & No of patients \\
\hline Generalized & $3(20 \%)$ \\
\hline Fronto-occipital & $3(20 \%)$ \\
\hline Occipital & $9(60 \%)$ \\
\hline
\end{tabular}

Table 8: total dose of diclofenac required during 72 hours following lumbar puncture

\begin{tabular}{|l|l|}
\hline Injection diclofenac & No of patients \\
\hline $75 \mathrm{mg}$ & $5(33.3 \%)$ \\
\hline $150 \mathrm{mg}$ & $7(46.6 \%)$ \\
\hline $225 \mathrm{mg}$ & $3(20 \%)$ \\
\hline
\end{tabular}

\section{Discussion}

Spinal anaesthesia is a popular anaesthetic technique with a low complication rate but it carries the special risk of post dural puncture headache (PDPH). The incidence of PDPH has been reported from $1.2 \%$ to $46 \%$ with intentional dural puncture and may be as high as $78 \%$ with unintentional puncture with large bore needle. Whereas the reported $7.8 \%$ to $37.2 \%$.

The most widely accepted theory concerning the cause of PDPH is based on concept of loss of CSF through a dural tear. When the patient assumes an upright posture lumbar CSF fluid pressure normally increases from 5 to $15 \mathrm{~cm}$ of $\mathrm{H} 2 \mathrm{O}$ in the horizontal position to about $40 \mathrm{~cm}$ of $\mathrm{H} 2 \mathrm{O}$ in the sitting position. Owing to the pressure gradient between the intradural and extradural space, spinal fluid is loss into epidural space as long as hole in the dura matter exist. The amount of CSF lost and therefore the incidence of PDPH depends on many factors which include needle dependent factors such as its size, type and bevel direction to the dural fibers and patients related factors such as patient's age, sex and BMI. In our study we evaluated influence of age and gender on the incidence of PDPH. ${ }^{[5,6]}$

In our study we included 186 patients of ASA grade I and II out of which total 15 patients had PDPH according to defined criteria. The overall incidence of PDPH in present study with 25 gauze needle is $8.06 \%$. our findings were similar to the many studies done previously like Lybecker et al. ${ }^{[1]}(7.3 \%)$; O Despond $(9.3 \%) ;{ }^{[2]}$ Vallego et al $(8.7 \%) ;{ }^{[3]}$ Tariq Malik et al $(5 \%) ;{ }^{[4]}$ Rasmussen et al $(12.6 \%) ;{ }^{[5]}$ shah VR8 $(14 \%)$ and Vandaum Drippers et al, ${ }^{[6]}(11 \%)$ In some studies there is higher incidence of PDPH than our study like Kortum et $\mathrm{al}^{[12]}(30.96 \%)$; J Singh et al. ${ }^{[1]}(25 \%)$. Few studies like M Seeberger et al. (1.5\%); Tariq Malik et al, ${ }^{[4]}$ (5\%) show the overall incident of PDPH less than that seen in our study. This difference in incidence of PDPH may be due to difference in the population characteristic, expertise of person performing the spinal anaesthesia, intraoperative variables, low sample size and difference in the methodology in study and may be the psychosomatic component of PDPH. In our study the incidence of PDPH in young age was
$12.12 \%$ and I old age group was $3.44 \%$. This difference was clinically as well as statistically significant with $\mathrm{p}<0.05$.

In the study done by Vandam and Drippes et al, ${ }^{[6]}$ in 8460 patients in whom total 10,098 spinal anaesthetic was given shown overall incidence of PDPH was $11 \%$. They concluded that old age person and males were least susceptible to develop PDPH than younger patient and females. This observation was statistically significant with our study.

John Lynch et al, ${ }^{[10]}$ in 1991 studied 200 orthopedic patients aged between 15 to 84 years of age and evaluated that incidence of PDPH was $2 \%$ and $4 \%$ with 22 gauze and 25 gauze whitacare spinal needle respectively. The results shows that incidence of PDPH was $5.6 \%$ in female and $0.9 \%$ in male and 4 out of 5 patients develop PDPH were younger than 45 years. So they concluded that PDPH is more common in young group. Our results are similar to this study.

Kang et al, ${ }^{[9]}$ studied 730 patients of age group 18 to 86 years who underwent spinal anaesthesia with 26 and 27 gauze quincke needle and observe that overall incidence of PDPH was $9.6 \%$ with 26 gauze needle. They also observe that incidence of PDPH in young age group of $<40$ years of age was $11.9 \%$ and in old age group $>40$ years was $4.8 \%$. so this study is statistically significant with our study.

The extent of gender as an independent risk factor for development of PDPH is not clear. Although it is not apparent why non pregnant female would have higher incidence of PDPH, there may be several physiology, anatomical, or psychological possibility to explain the higher incidence of PDPH in non pregnant female. 1) Female subjects seem to process nociceptive information differently than male subject. 2) It seems that female subject generally exhibit greater sensitivity to experimental noxious stimuli than male. 3) Females also have higher temporal summation of mechanically evoked pain, indicating that female may demonstrate greater degree of central sensitization compare with male. 4) In addition to gender differences in nociceptive threshold and processing, there may be psychological factor that may contribute to some of the difference seen in experimentally induced pain. 5) Socially learned, gender role expectation of pain may induce the incidence of retrograde pain because male subjects are less likely to disclose the presence of pain than female. 6) Post operatively females report a higher incidence of headache and pain despite possibly having a greater analgesic response to opioids than male. Therefore, both biological and psychological factors may contribute to the difference in perception of pain. 7) Vasodilatation of cerebral vessels normally occurs with patients with PDPH as a homeostatic mechanism to compensate for CSF loss. 7) Finally, younger (30-40yr), presumably premenopausal women have a significantly higher cerebrovascular reactivity compared with older women $(50-60 \mathrm{yr})$ and men. ${ }^{[7]}$

In our study the maximum severity of PDPH in all patients varies between grade II to grade III according to the grading given by Crocker et. al. out of 15 patients 11 (73.3\%) patients had moderate and $4(26.6 \%)$ patients had severe PDPH. Severe headache was usually accompanied by nausea and vomiting. Severity of PDPH was usually varies between mild to moderate between many studies. None of the patients in the both group had very severe headache of 
grade IV. Severity is more in young age group and more in females.

In present study time of onset of development of PDPH was between 24 to 48 hours after dural puncture. Out of 15 patients $5(33.3 \%)$ had PDPH in 24 hours, $6(40 \%)$ had PDPH in 30 hours and $4(26.6 \%)$ had PDPH in 36 hours. None of the patients develops PDPH before 24 hours or after 48 hours. The location of PDPH was occipital in $9(60 \%)$ patients, fronto-occipital in $3(20 \%)$ and generalized in 3 (20\%) patients.

PDPH cases were initially treated with bed rest, oral and intravenous hydration. Patients were treated with intravenous injection Diclofenac $75 \mathrm{mg}$ when headache was moderate to severe. Out of 15 patients, $7(46.6 \%)$ patients needed 150 mg, $5(33.3 \%)$ patients needed $75 \mathrm{mg}$ and $3(20 \%)$ patients needed $225 \mathrm{mg}$ of total diclofenac. All the patients who develop PDPH responded well with PDPH. None of the patients in our study required epidural blood patch. None of the 15 patients who develop PDPH had other symptoms associated with it like cranial nerve palsy, neck stiffness, vertigo, tinnitus, diplopia or cortical blindness.

\section{Conclusion}

The overall incidence of PDPH in Civil Hospital, Sola, and Ahmedabad was $8.06 \%$. The incidence of PDPH in young patients was $12.12 \%$ and in old patients were $3.44 \%$. Thus the incidence of PDPH was significantly but inversely proportional to the age of patients. The incidence of PDPH in female was $12.5 \%$ and in male was $4.08 \%$. Thus female significantly have more risk of developing PDPH. The onset o PDPH after dural puncture among the patients who develop PDPH occurred within 24 hours in $33.3 \%$, within 30 hours in $40 \%$ and within 36 hours in $26.6 \%$ of patients. PDPH was most commonly located in occipital region in $60 \%$ of patients. Severity of PDPH was mild to moderate. In $73.3 \%$ of patients the maximum severity was grade II. Nausea and vomiting was associated with severe PDPH. No patients develop any other associated symptoms.

\section{References}

1. Lybecker H, Djernes M, Schmidt JF. Postdural puncture headache. Acta Anaesthesiol Scand 1995;39:605-12.

2. Oliver Despond MD, Pascal Meuret, Gisele Hemmings. Postdural puncture headache after spinal anaesthesia in a young orthopaedic out patient using 27 gauze spinal needle. Can J Anasth 1998/ 45:11/ pp1106-1109.

3. Manuel C. Vallego, Gordon L, Mandell, Daniel P. Sabo and Shivam Ramnathan. Postdural puncture headache. A randomized comparison of 5 spinal needles in obstetric patients. Anaesth Analg 2000;91:91620.

4. Dr.Tariq Malik, col. Dr. M. A. Khan, brig. Dr. A. Iqbal. Postspinal headache; comparing needle of 25 and 27 Gauze for incidence of post spinal headache. Professional med J September 2007; 14(3):441-447.

5. Rasmussen BS, Blom L, Hansen P, Mikkelsen SS. Post spinal headache in young and elderly patients. Two randomized, double blind studies that compare 20 and 25 Gauze needle. Anaesthesia. 1989 july;44(7):571-573.

6. Vandam LD, Drippes RD 1956 long term follow up of patients who receive 10098 spinal anesthetics: syndrome of decrease intra cranial pressure JAMA 161:586-591.

7. Miller's Anaesthesia 7th addition.

8. Shah VR, Bhosle GP. Spinal anesthesia in young patients : evaluation of needle Gauze and design in technical problems and Postdural puncture headache. Anaesthesiol Analg. 2010;16(3).

9. Kang SB, Goodnaugh De, Lee YK, Olson RA et al. comparison of 26 and 27 Gauze spinal needle for spinal anaesthesia for ambulatory surgery patients. ANAESTHESIOLOGY 1992; 76:734-8.

10. J. Lynch, i. Krings-ernst, k. strick et al. use of 25 Gauze whitcate needle to reduce the incidence of postdural puncture headache British Journal of Anaesthesia 1991; 67:690-93.

11. J. Singh, S Ranjit, S Shrestha et al. postdural puncture headache Journal of Institute of Meicine, August, 2010;32:2.

12. Kortum K, nolte H, KrnkmannHj (1982) Sex difference related complication rate after spinal anaesthesia Reg Anaest 5:1-6.

13. V. K. Grover, MD, MNAMS, Indu Bala, MD et al. postdural puncture headache following spinal anaesthesia: comparison of 25 Gauze Vs 29 Gauze spinal needles Bahrain Medical Bulletin, vol.24, No. 4, December 2002.

Copyright: () the author(s), publisher. Academia Anesthesiologica International is an Official Publication of "Society for Health Care \& Research Development". It is an open-access article distributed under the terms of the Creative Commons Attribution Non-Commercial License, which permits unrestricted non-commercial use, distribution, and reproduction in any medium, provided the original work is properly cited.

How to cite this article: Gandhi R, Shah A, Patel I. Effect of Age and Gender on Incidence of Post Spinal Headache. Acad. Anesthesiol. Int. 2019;4(1):38-41.

DOI: dx.doi.org/10.21276/aan.2019.4.1.9

Source of Support: Nil, Conflict of Interest: None declared. 